\begin{tabular}{llllll}
\multicolumn{5}{c}{ 長崎大学医学部第一内科 } & \\
森田 & 茂樹 & 瀬戸 & 牧子 & 原 & 恵子 \\
井手 & 芳彦 & 石丸 & 忠彦 & 和泉 & 元衛 \\
过畑 & 光宏 & 長㳻 & 重信 & &
\end{tabular}

\title{
A CASE OF ACUTE WATER INTOXICATION DEVELOPED IN A HEALTHY ADULT
}

\author{
Shigeki MoRITA, MD, Makiko SETO, MD, Keiko HaRA, MD \\ Yoshihiko IDE, MD, Tadahiko IsHIMARU, MD, Motomori IZUMI, MD \\ Mitsuhiro Tsujihata, MD and Shigenobu NAGATAKI, MD \\ The First Department of Internal Medicine, School of Medicine, \\ Nagasaki University, Nagasaki
}

\begin{abstract}
概要 民間療法として大量の领水之水浣腸を行ない，急性水中毒症の発症をみた健康成人例を 経験した。症例は25才，男性。昭和54年上り健康增進を信じて大量领水と水浣腸を始めた。昭 和 55 年 5 月 27 日大量発汗後約 30 分で $2 l$ の飲水と 81 水浣腸を行ない, 四肢のこわばり感等出現 したのら呼名反応なくなつたため当科入院となつた。入院時血清 $\mathrm{Na} 124 \mathrm{mEq} / l$ と低 $\mathrm{Na}$ 血症を 呈していた。 また入院前 24 時間以上水分摄取がなかったにもかかわらず， $\mathrm{Na}$ 濃度 $6 \mathrm{mEq} / \mathrm{l}$ と低 浸透圧尿の多量排泄 ( 1 日量 $5300 \mathrm{ml}$ ) が2 が回復した，以上より急性水中毒症と診断した，急性水中毒症は何らかの基礎疾患を有する例 にみられやすく，その成因は細胞外液の急激な低浸透圧化のために水分が細胞内に移動し，脳 浮腫をきたすためとされている，本例では発症後水分制限がなされたこと，高張ブドウ糖・Na 製剤輸液を使用したことに加古て, 急激な利尿に上り細胞外液の浸透王改善が得られ救命し得 たと思われる。なお第 3 病日に行なつた腰椎穿刺では, $\mathrm{Na}$ 濃度 $97 \mathrm{mEq} / l, \mathrm{Cl}$ 濃度 $82 \mathrm{mEq} / l$, 総 蛋白量 $12 \mathrm{mg} / \mathrm{dl}$ と低浸透王であつた。血清Na濃度の改善よりも脳細胞内括よび脑尙䯣液の浸透 压改善は遅れると考兄られる。入院時検查成績で総ビリルビン $4.0 \mathrm{mg} / \mathrm{dl}, \mathrm{CPK} 1815 \mathrm{mU} / \mathrm{ml}$, $\mathrm{LDH} 507 \mathrm{mU} / \mathrm{ml}$, GOT $67 \mathrm{mU} / \mathrm{ml}$ 等の異常値を示していたが，办中毒症との関係については現 在の所明らかではない。
\end{abstract}

\section{緒 言}

水中毒症は水分の大量掑取および体内眝留によ り，痉挛・意識障害など種々の神経症状をきたす 疾患であり，1922年Weirらによつて命名された1). その後, 精神病患者の大量领水 ${ }^{233)}$. 小肾への浣 腸4)51 ・術後輸液 ${ }^{6)} \cdot \mathrm{SIADH}^{7) 81}$ ・種々の内分泌疾

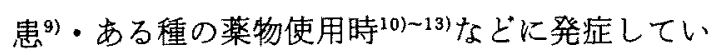

〔昭和 57 年 3 月 18 日受稿〕

本論文の要旨は第172回日本内科学会九州地方会 （昭和56年 2 月 28 日）に発表した。
るが，多くは何らかの基礎疾患を有する患者例で ある，著者らは大量の领水と水浣腸に上り，いわ ゆる急性水中毒症を発症し，救急外来定受診した 健康成人の 1 例を経験したので報告する。

$$
\text { 症例 }
$$

患者：25才, 男性, 農夫。

主訴：意識障害.

家族歴：特記事項なし。

既往歴：特記事項なし。

現病歴：昭和 54 年 2 月より健康増進を信じて 
自家製の水（患者は飲水によつて腰痛が治つたた めその薬理作用を信じていたが，この水は水道水 に電流を通しただけのものであり, 水道水と著変 ないと思われる。)を飲水し始め, 農薬使用時など には体内からの農薬排除の目的で同水による浣腸 も行なつていた。その後徐々に増量傾向にあつた が，同年 6 月農薬散布後飲水之水浣腸を行ない両 下肢のこわばり感, 胸内苦悶感, 呕吐等が出現し 傾眼状態となつた。同様の症状が友人 2 人にも出 現したため, 以後は同水に食塩を添加して浣腸を 行なつていた。昭和55年 5 月 27 日，この日は暑い 日であつたが予防着を着用し, 約10時間の農薬散 布を行なつた。この間大量の発汗をみたが，全く 领水しなかつた. 午後 8 時頃帰宅し風呂場で約 $2 l$ の领水と 81 の水浣腸を約 30 分ほどで行なつた。 の後徐々に四肢のこわばり感, 胸内苦悶感, 数回 の呕吐が出現し，傾眠状態となつた。翌28日午前 2 時には呼びかけに反応しなくなつたため同日午 前 5 時近医に入院となつた。同院入院時尿糖陽性 で糖尿病性昏睡を疑い, lente insulin40単位使用 後経過観察していたが改善しないため, 同日午後 8 時当院救急外来を受診し, 同11時当科入院とな つた。

入院時現症：体格は良(第 5 病日の身長 170 $\mathrm{cm}$, 体重 $66 \mathrm{~kg}$ ), 呼名反応なし. 痛覚刺激に対して は激しく体動し開眼した。皮䖉は暖でやや湿潤, 脈拍 $57 /$ 分整, 血圧 $130 / 90 \mathrm{mmHg}$, 呼吸 $21 /$ 分, 深呼 吸, 顔面紅潮, 負血なし。眼球結膜は黄染あり。 瞳孔正円で対光反射正常, 眼球偏位なし. 胸部打 聴診異常なし、肝脾触知せず，腱反射正常で病的 反射なし、下肢に軽度浮腫を認めた。

検查成績および経過：28日救急外来受診時の 検査成績は, $\mathrm{Hb} 14.7 \mathrm{~g} / \mathrm{dl}$, 白血球数 $10100 / \mathrm{mm}^{3}$, $\mathrm{Na} 124 \mathrm{mEq} / l, \mathrm{~K} 3.0 \mathrm{mEq} / l, \mathrm{Cl} 86 \mathrm{mEq} / l$, 血糖 73 $\mathrm{mg} / \mathrm{dl}$. 尿検査では比重 1007 , 蛋白 (土), 糖 (一) で多尿、胸部レントゲン線像, 心電図に著変なし。 頭部CTスキャンは, 図 1 に示すごとく, はつきり した脳浮腫像ではなかつた。血液ガス分析では, $\mathrm{pH}$ 7.49.0, $\mathrm{PO}_{2}$ 93.7TORR, $\mathrm{Pco}_{2}$ 34,0TORR, $\mathrm{HCO}_{3}{ }^{-} 25.7 \mathrm{mEq} / l$ であつた.

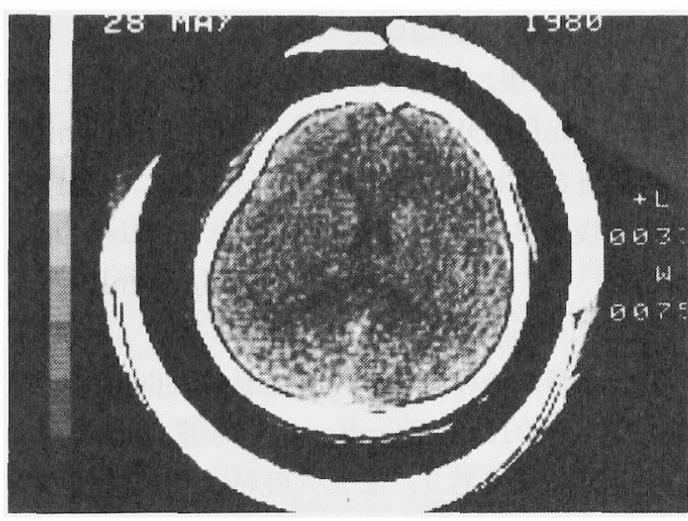

図 1. 入院時頭部CT像. 正常状態の患者頭部CT像と 比較して著变なし。

低Na血症および低比重多尿より水分過剰状態 が予想されたが，上記病歴は入院時点では聴取で きなかつたこと拉よび発症より24時間以上水分摂 取がなされなかつたこと，多量の低比重尿の排泄 をみたことより高張食塩水は使用せず，Na濃度 $130 \mathrm{mEq} / /$ の輸液剤にて点滴確保し, 経過観察し た。な打insulin使用のため, 低血糖状態の関与も 考えられたため，救急外来で $20 \%$ 和よび $50 \%$ のブ ドウ糖液をおのおの $40 \mathrm{ml}, 60 \mathrm{ml}$ 使用したが症状の 改善なく，その後血糖は正常值であつたことが判 明した。翌29日早朝の検査成績は表 1 に示すごと

表 1 。臨床検査所見

\begin{tabular}{|c|c|c|c|c|c|}
\hline 尿 & $\begin{array}{l}\text { 比重 } \\
\text { 量 }\end{array}$ & $\frac{1008}{1900 \mathrm{ml} / 9 \mathrm{~h}}$ & \multirow{2}{*}{ 血 } & $\begin{array}{l}\text { GOT } \\
\text { GPT }\end{array}$ & $\begin{array}{l}67 \mathrm{mU} / \mathrm{ml} \\
21 \mathrm{mU} / \mathrm{ml}\end{array}$ \\
\hline & \multicolumn{2}{|c|}{ 潜血便なし } & & $\mathrm{LDH}$ & $\underline{507} \mathrm{mU} / \mathrm{ml}$ \\
\hline \multirow{6}{*}{$\begin{array}{c}\text { 検 } \\
\text { 血 } \\
\text { 一 } \\
\text { 般 }\end{array}$} & $\mathrm{RBC}$ & 459 万/ $\mathrm{mm}^{3}$ & 液 & Alk-P-as & se $133 \mathrm{mU} / \mathrm{ml}$ \\
\hline & $\mathrm{Hb}$ & $14.4 \mathrm{~g} / \mathrm{dl}$ & \multirow[b]{2}{*}{ 生 } & LAP & $43 \mathrm{mU} / \mathrm{ml}$ \\
\hline & $\mathrm{Hct}$ & $40.4 \%$ & & $\gamma-\mathrm{GTP}$ & $6 \mathrm{mU} / \mathrm{ml}$ \\
\hline & WBC & $10700 / \mathrm{mm}^{3}$ & \multirow{2}{*}{ 化 } & $\mathrm{Ch}-\mathrm{E}$ & $0.79 \Delta \mathrm{pH}$ \\
\hline & Th & 24.5 万 $/ \mathrm{mm}^{3}$ & & T-chole & $125 \mathrm{mg} / \mathrm{dl}$ \\
\hline & B.S.R & $5 \mathrm{~mm} / \mathrm{h}$ & 学 & & $\underline{42} \mathrm{mg} / \mathrm{dl}$ \\
\hline & CRP & $(+)$ & 検 & Creat. & $0.7 \mathrm{mg} / \mathrm{dl}$ \\
\hline \multirow[b]{2}{*}{ 血 } & B S & $85 \mathrm{mg} / \mathrm{dl}$ & \multirow{3}{*}{ 査 } & $\mathrm{S}-\mathrm{Fe}$ & $58 \mu \mathrm{g} / \mathrm{dl}$ \\
\hline & $T B$ & $4.0 \mathrm{mg} / \mathrm{dl}$ & & $\mathrm{NH}_{3}$ & $75.5 \mu \mathrm{g} / \mathrm{dl}$ \\
\hline 液 & D B & $\underline{1.6 \mathrm{mg} / \mathrm{dl}}$ & & $\mathrm{CPK}$ & $1815 \mathrm{mU} / \mathrm{ml}$ \\
\hline 生 & TP & $6.5 \mathrm{~g} / \mathrm{dl}$ & & & \\
\hline 化 & $\mathrm{Al}$ & $64.7 \%$ & \multirow[b]{2}{*}{ 電 } & $\mathrm{Na}$ & $128 \mathrm{mEq} / \mathrm{l}$ \\
\hline 学 & $\alpha_{1}-g l$ & $5.0 \%$ & & $\mathrm{~K}$ & $3.6 \mathrm{mEq} / l$ \\
\hline 検 & $\alpha_{1}-\mathrm{gl}$ & $6.7 \%$ & 解 & $\mathrm{Cl}$ & $\underline{90} \mathrm{mEq} / \mathrm{l}$ \\
\hline \multirow[t]{2}{*}{ 査 } & $\beta-\mathrm{gl}$ & $10.9 \%$ & \multirow{2}{*}{ 質 } & $\mathrm{Ca}$ & $9.1 \mathrm{mg} / \mathrm{dl}$ \\
\hline & $\gamma-g l$ & $12.6 \%$ & & $\mathrm{P}$ & $2.6 \mathrm{mg} / \mathrm{dl}$ \\
\hline
\end{tabular}


く低比重多尿，低 Na血症であつた。主た総ビリル ビン $4.0 \mathrm{mg} / \mathrm{dl}$, 直接ビリルビン $1.6 \mathrm{mg} / \mathrm{dl}, \mathrm{CPK}$ $1815 \mathrm{mU} / \mathrm{ml}, \mathrm{LDH} 507 \mathrm{mU} / \mathrm{ml}$, GOT $67 \mathrm{mU} / \mathrm{ml}$ 等 の異常値を示していた。同日午後 1 時に一過性の 意識回復をみたが，この時の血清では $\mathrm{Na} 134$ $\mathrm{mEq} / l, \mathrm{Cl} 95 \mathrm{mEq} / l, \mathrm{ADH} 0.5 \mu \mathrm{U} / \mathrm{ml}$ 以下, $\mathrm{ACTH} 20.9 \mathrm{pg} / \mathrm{ml}$ であつた。 また同日午前 6 時よ り午後 6 時までの 12 時間の蓄尿量は $2800 \mathrm{ml}$ で, 比 重 1007 , その Na濃度 $6 \mathrm{mEq} / l$, Cl濃度 $10 \mathrm{mEq} / l$ と 低浸透王多尿であり，また入院時より24時間の排 尿量は $5300 \mathrm{ml}$ であつた。同日午後 5 時より意識レ ベルの改善がみられ，第 4 病日の31日には完全に 正常化した．以上臨床経過をまとめてみると，(1) 大量の水搷取が行なわれた。(2) 発症後24時間以上 水分撕取がなされなかつたにもかかわらず頻尿が みられた。 (3) 入院時低Na血症を呈していた。 (4) 低 $\mathrm{Na}$ 尿の多量排泄により低Na血症が改善し，そ れに伴つて意識回復がみられたことである（図 2 )。な敃第 3 病日 (30日) に行なつた腰椎穿刺で は, 王 $125 \mathrm{mmH}_{2} \mathrm{O}$, 細胞数 $1 / 3$, 糖 $47 \mathrm{mg} / \mathrm{dl}$, 総蛋 白 $12 \mathrm{mg} / \mathrm{dl}, \mathrm{Na}$ 濃度 $97 \mathrm{mEq} / l, \mathrm{Cl}$ 濃度 $82 \mathrm{mEq} / l$ と 低浸透圧であつた，症状改善後に行なつた赤血球 抵抗試験，50g GTTは正常であつた。

\section{考案}

急性水中毒症の報告は，その汪とえどが精神病 患者の大量飲水例, 巨大結腸児等小児への浣腸例, $\mathrm{ADH}$ 過剩状態での水分拄取例である。近年は薬物 使用例 (chlorpropamideなどのADH様作用を有 するもの，またはADH分泌作用を有するものや， thiazideなど塩類㖪失作用を有するもの）での報

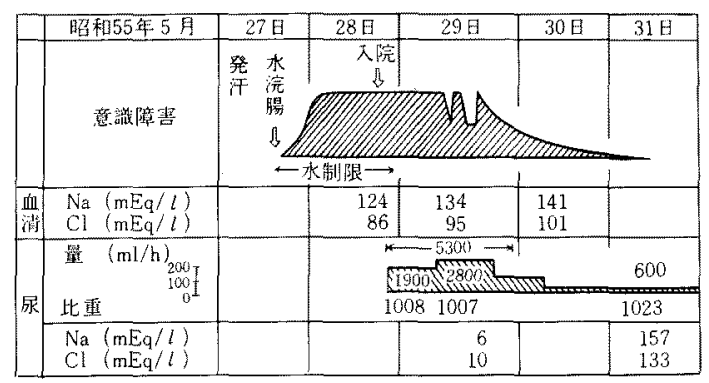

図 2, 臨床経過
告も増加している。本症の症状としては，呕吐， 注意力低下, 筋力低下, 異常行動, 疼挛, 意識障 害などである，重症例では死亡する例す多く，致 命率の高い疾患としてその成因治療について注目 されるよらになつた㣙17). Arieffをはじめ多くの 報告者 ${ }^{16) 18}$ によれば，水中毒症の成因は以下のご とくである。細胞外液が水分過鄱状態となると $\mathrm{Na}$ イオンその他の溶質が希釈され，浸透圧低下が起 きる。この時細胞内外を自由にからするやかに移 動できる水分が細胞外液から細胞内液へ移動し， 細胞浮腫を生じる。そのため脳浮腫による神経症 状を呈すると考穴られている，水中毒症の発症和 よび重症度は，水分の掑取量，細胞外液に含禾れ る溶質の量，摄取に要した時間および水分調節機 構の状態によつて決まる219)16)17)。本症では発汗に よる塩類喪失時に短時間で多量の飲水と水浣腸を 行ない，急激な低浸透王血浆（低Na血症）を生じ 急性水中毒症を発症したと思われる，急性水中毒 症の治療には，脳細胞内から細胞外液への水分移 動が必要であり, 水分制限, 高張食塩水の静注, 高張ブドウ糖・mannitol 等が用いられてい $3^{14 / 15116 / 19 / 20)}$ ，ここで水分調節機能異常一ADH過 剩状態や腎上りの水分排泄障害一のある例では， 水分過鄱状態が遷延しやすく重症化しやすい。一 方本症例のように，水分調節機能正常例では生体 防御として多量の利尿を得ることになる ${ }^{18)}$ 。前者 では低浸透圧血浆で，正なたは高浸透圧尿となる が，後者では低漫透压尿となり，両者は区別して 扱うべきもと考えられる、検查成績でみられた $\mathrm{CPK}, \mathrm{LDH}$ (LDHアイソザイム 2 優位)，GOT拉 よび総ビリルビン等の異常検査值は, CPK 120 $\mathrm{mU} / \mathrm{ml}$ 除いてすべて入院中に正常化した。水中 毒症例でこのような報告はなく，また昭和 56 年 2 月の検査でも $\mathrm{CPK} 122 \mathrm{mU} / \mathrm{ml}$, 総ビリルビン 2.1 $\mathrm{mg} / \mathrm{dl}$ と軽度異常值を示して和り，水中毒症との 関係については現在の所, 明らかではない。

\section{結 語}

著者らは，25才の健康男子に発症した，いわゆ る急性水中毒症の 1 例を経験したので若干の文献 的考察を加克て報告した。 


\section{文献}

1) Weir JF, et al: Studies in diabetes insupidus, water balance and water intoxication. Arch Intern Med 29: 306, 1922.

2) Barlow ED and De Wardener HE: Compulsive water drinking. Quart J Med 28: 235, 1959.

3) Hobson JA and English JT: Self-induced water intoxication. Ann Intern Med 58: 324 , 1963.

4) Richards MR and Hiatt RB: Untoward effects of enemata in congenital megacolon. Pediatrics $12: 253,1953$.

5) Editorial: The hazard of water enemas. Lancet $1: 559,1959$.

6) Zimmerman $\mathrm{B}$ and Wangensteen $\mathrm{OH}$ : Observations on water intoxication in surgical patients. Surgery $31: 654,1954$.

7) Schwartz WB, et al: A syndrome of renal loss and hyponatremia probably resulting from inappropriate secretion of antidiuretic hormone. Amer J Med Sci 23 : 529, 1957.

8) Goldberger $E$ : Water excess syndromes, Inappropriate $\mathrm{ADH}$ secretion syndromes. A primer of water, electrolyte and acid-base syndromes. 6th ed Lea and Febiger, Philadelphia, 1980, p66.

9) Wynn V and Gsarrod O: Spontaneous and induced water intoxication in two cases of hypopituitarism. Brit Med J 1: 505, 1955.

10) Fichman MP, et al: Diuretic-induced hyponatremia. Ann Intern Med 75: 853, 1971.

11) Garcia $M$, et al: Chlorpropamide-induced water retention in patients with diabetes mellitus. Ann Intern Med 75: 549, 1971.

12) Robertson GL, et al: Vincristine neurotoxicity and abnormal secretion of antiduretic hormone. Arch Intern Med 132: 717, 1973.

13) Radó JP: Water intoxication during carbamazepine treatment. Brit Med J 3: 479, 1973.

14) Goldberger E: Water excess syndromes. A primer of water, electrolyte and acid-base syndromes. 6th ed Lea and Febiger, Philadelphia, 1980, p58.

15) Wynn $V$ and Rob CG: Water intoxication: differential diagnosis of hypotonic syndromes. Lancet 1: 587, 1954.

16) Arieff AI, et al: Neurological manifestations and morbidity of hyponatremia: Correlation with brain water and electrolytes. Medicine 55 : 121, 1976.

17) Lipsmeyer E and Ackerman GL: Irreversible brain damage after water intoxication. JAMA 196: $286,1966$.

18) Swanson $A G$ and Iseri $O A$ : Acute encephalopathy due to water intoxication. New Engl J Med 258: 831, 1958.

19) Stormont JM and Water-house $C$ : The genesis of hyponatremia associated with marked overhydration and water intoxication. Circulation $24: 191,1961$.

20) Ariel IM : Effects of a water load administered to patients during the immediate postoperative period, Arch Surg 62:303, 1951. 